\title{
Canada needs a national suicide prevention strategy
}

\author{
Laura Eggertson BA BJ, Kirsten Patrick MB BCh DA
}

$\mathrm{H}$ eartsick over the loss of more than 800 Inuit who have seen no way through their pain except to end their own lives, ${ }^{1}$ Inuit Tapiirit Kanatami (ITK), the national Inuit political association, recently released an evidence-based suicide prevention strategy. ${ }^{2}$ The culturally specific strategy is intended to address the glaring void that has been left by Canada's lack of a national suicide prevention strategy.

Suicide is the second leading cause of death among all young people aged 15-34 years in Canada. ${ }^{3}$ Among some indigenous populations, rates are staggeringly high. In Nunatsiavut, northern Labrador, suicide rates are 25 times the national average. In Nunavut and Nunavik, they are 10 times the national rate. Among young Inuit men in Nunavut, rates rise to as high as 40 times those of their nonInuit counterparts, while in other First Nations communities, the rates may be 5 to 6 times the national average. ${ }^{1,2}$ News of clusters of suicides in Kuujjuaq, Que., Woodstock, Ont. and the Neskantaga First Nation may leave most Canadians feeling helpless before what seems an intractable problem.

ITK's leaders, however, know that there is good evidence to show that suicide is preventable and that high rates can be reduced. That's why, when developing a strategy for the country's four Inuit regions, they incorporated elements from models that have been successful around the world including within our own borders.

In the decade after publishing its own prevention strategy in 1998, Quebec cut suicide rates among youth aged 15-19 years in half. Overall, suicide rates dropped by a third. ${ }^{4}$ The strategy did not, however, reduce rates among Quebec's indigenous populations, which had opted out of the provincial strategy.

The World Health Organization (WHO) has urged all countries to develop national suicide strategies. Its 2014 report on suicide prevention as a public health imperative summarized evidence on both risk and protective factors, and appraised effective policy interventions. ${ }^{5}$ Culture can be both a risk and a protective factor; historical trauma increases risk, and strong cultural ties can provide support. ${ }^{6}$

Among 21 member nations of the Organisation for Economic Co-operation and Development (OECD) that had implemented government-led national strategies by 2011 , suicide rates decreased overall, with the greatest declines among youth and older persons - the two demographic groups at greatest risk in Canada. ${ }^{7}$

ITK's strategy ${ }^{2}$ identifies specific risks for Inuit and incorporates the protective factors WHO has identified. The strategy cannot, however, accomplish its goal of lowering suicide rates to the national average or below without an overarching national strategy that will coordinate federal and provincial-territorial activities.

Suicide prevention encompasses more than mental health. It extends beyond communities where rates are exceptionally high. Improving upstream factors associated with suicide - such as identifying children at risk of or suffering from sexual and physical abuse early, and intervening through culturally appropriate child development and school-based programs - will require coordination among the education, justice, employment and social welfare sectors. ${ }^{8}$ That's the job of a national suicide prevention strategy.

At the end of 2012, Canada passed the Federal Framework for Suicide Prevention Act. The legislation prescribes federal consultations with provincial-territorial governments and nongovernment organizations to inform the development of a federal framework for suicide prevention. A framework is not a strategy, however. It does not bring necessary resources to bear, nor does it mandate the federal and provincial-territorial actions and multisectorial partnerships required to underpin effective suicide prevention across Canada. Strategies provide clear roadmaps, with goals, timelines, resources, assigned responsibilities and a robust plan for their evaluation.

Substantial evidence exists to guide the creation of a strong suicide prevention strategy in Canada. It is noteworthy that the incumbent government, when in Opposition, called for such a strategy. Although the new federal government's 2016 budget showed commitment to tackling social determinants of health that underpin health inequalities, it contained few provisions for addressing mental health issues.

The 2017 budget must pledge the means to developing a national suicide prevention strategy, starting with funds to create a centre of expertise that will engage with leading indigenous organizations, such as ITK and the Assembly of 


\section{EDITORIAL}

First Nations, and build on existing strategies such as Quebec's, to address the needs of communities and plan the broader infrastructure that is required to address properly what has become a national public health crisis.

\section{References}

1. Eggertson L. Inuit suicide prevention strategy strives to save lives. CMAJ 2016;188:861-2.

2. National Inuit suicide prevention strategy. Ottawa: Inuit Tapiriit Kanatami; 2016. Available: www.itk.ca/wp-content/uploads/2016/07/ITK-National-Inuit-Suicide -Prevention-Strategy-2016.pdf (accessed 2016 Aug. 8).

3. Health at a glance. Suicide rates: an overview. Ottawa: Statistics Canada; 2015. Cat no 82-624-X. Available: www.statcan.gc.ca/pub/82-624-x/2012001/article/11696 -eng.htm (accessed 2016 Aug. 8).

4. Légaré G, Gagné M, Perron PA, et al. La mortalité par suicide au Québec: 1981 à 2012 — mise à jour 2015. Quebec: Bureau d'information et d'études en santé des populations, Institut national de santé publique du Québec; 2015:4. Available: www.inspq .qc.ca/pdf/publications/1939_Mortalite_Suicide_2015.pdf (accessed 2015 Mar. 28).

5. Preventing suicide: a global imperative. Geneva: World Health Organization; 2014.
Available: www.who.int/mental_health/suicide-prevention/world_report_2014 /en/ (accessed 2016 Aug. 8)

6. Clifford AC, Doran CM, Tsey K. A systematic review of suicide prevention interventions targeting indigenous peoples in Australia, United States, Canada and New Zealand. BMC Public Health 2013;13:463.

7. Matsubayashi T, Ueda M. The effect of national suicide prevention programs on suicide rates in 21 OECD nations. Soc Sci Med 2011;73:1395-400.

8. Chachamovich T, Kirmayer LJ, Haggarty JM, et al. Suicide among Inuit: results from a large, epidemiologically representative follow-back study in Nunavut. Can J Psychiatry 2015;60:268-75.

Competing interests: None declared for Eggertson. See www.cmaj.ca/site/ misc/cmaj_staff.xhtml.

Affiliations: Freelance reporter (Eggertson), Ottawa, Ont.; Deputy editor (Patrick), CMAJ

Correspondence to: CMAJ editor, pubs@cmaj.ca

CMAJ 2016. DOI:10.1503/cmaj.160935 